\title{
Fishes learn aversions to a nudibranch's chemical defense
}

\author{
Jeremy D. Long, Mark E. Hay* \\ School of Biology, Georgia Institute of Technology, 310 Ferst Drive, Atlanta, Georgia 30332-0230, USA
}

\begin{abstract}
The nudibranch Doriopsilla pharpa was rejected as food when tethered in the field and when offered to 2 species of co-occurring crabs (the lesser blue crab Callinectes similus and the mud crab Panopeus herbstii) and 2 species of co-occurring fishes (the mummichog Fundulus heteroclitus and the striped blenny Chasmodes bosquianus) in the laboratory. When the fishes were offered squid-based artificial food containing nudibranch extracts (i.e. defended food), both species initially consumed this food, but rapidly developed aversions in subsequent feedings. Although both fishes rapidly learned to reject the food, they learned using different cues. The striped blenny Chasmodes bosquianus regurgitated following the initial feeding and then avoided all food made of squid regardless of whether or not it contained the extract. In contrast, the mummichog Fundulus heteroclitus did not regurgitate, and learned to avoid only food containing the extract; it still consumed squid-based food without the extract. Thus, the mummichog detected the deterrent chemical and avoided only defended food while the striped blenny was a less effective feeder, avoiding both defended and undefended food that tasted like squid. Bioassay-guided separation using the mummichog demonstrated that the sesquiterpene polygodial was responsible for the deterrent effects of the nudibranch extract. This metabolite also resulted in the striped blenny avoiding either squid- or tunabased food treated with this metabolite.
\end{abstract}

KEY WORDS: Fish behavior · Predator-prey interactions · Chemical ecology · Oyster reef

\section{INTRODUCTION}

Opisthobranch gastropods, such as nudibranchs, are well known for their secondary metabolites, which may be diet-derived (Slattery et al. 1998) or produced de novo (Cimino et al. 1983, Kubanek et al. 1997). Evidence is mounting that these compounds serve a defensive function that is important to both the ecology and evolution of this molluscan group (Faulkner \& Ghiselin 1983, Avila 1995, Cimino \& Ghiselin 1999). Over the past 2 decades, multiple studies have demonstrated the defensive benefit of these compounds by adding extracts and purified compounds to palatable food and recording how these metabolites altered the feeding behaviors of sympatric consumers (Pawlik et al. 1988, Cronin et al. 1995, Avila \& Paul 1997, Penney 2002). In these studies, consumers immediately rejected food treated with nudibranch compounds, suggesting that consumers were recognizing and avoiding the deterrent chemicals. However, selection for recognition of specific noxious metabolites may not always be the rule, as consumers could use visual cues or taste cues not directly related to the deterrent chemical to avoid prey that produce physiological distress following consumption (Young \& Bingham 1987, Launchbaugh \& Provenza 1993). If consumers detect and avoid specific noxious chemicals, then only prey containing those compounds will be defended. However, if consumers avoid prey that taste like, or look like, defended prey but do not cue on the specific compound that produces physiological distress, then consumers may be unable to selectively attack lessdefended individuals, and prey may be able to escape via chemical or visual mimicry (Cauley \& Schluter 2003, Howard \& Blomquist 2005). Which chemical cues are used by consumers in assessing prey, how con- 
sumers learn to assess the value of novel prey (e.g. introduced species, range extensions, populations evolving new defenses), and how these interactions affect consumer-prey interactions are poorly understood for marine systems. Under some conditions, innate preferences may be too restrictive, causing consumers to miss opportunities during variation in food composition and availability (Laska \& Metzker 1998) or allowing the ingestion of toxins as prey evolve resistance or as new, chemically-defended prey enter the habitat (Provenza et al. 2003). Learning provides an ecological response to changing prey availability and defenses by allowing consumers to add novel food to their diets while reducing the risk of consuming noxious food (Provenza 1995).

Learned food aversions occur in a diverse array of consumers including insects (Berenbaum \& Miliczky 1984), molluscs (Gelperin 1975), fishes (Gerhart 1991, Lindquist \& Hay 1995), reptiles (Burghardt et al. 1973), birds (Nicolaus et al. 1983), and mammals (Garcia et al. 1974, Bernstein 1978, Yoerg 1991), with the majority of research focusing on terrestrial species. Fishes, a group of important, generalist consumers that co-occur with nudibranchs, are well-known for their learning ability (Thacker et al. 1997, 1998, Crossland 2001, Warburton 2003) and may quickly develop aversions to food that cause regurgitation (Gerhart 1984, 1991, Lindquist \& Hay 1995). However, nudibranch metabolites that create such learned aversions in marine fishes are unknown.

Our goal was to study nudibranch chemical defenses within an ecologically realistic context by offering different co-occurring consumers nudibranchs, nudibranch extracts and deterrent nudibranch compounds at natural concentrations. We determined that a common nudibranch was unpalatable to many co-occurring consumers and that chemical extracts could create learned aversions in 2 species of predatory fishes. We evaluated: (1) which prey compounds caused aversive learning and (2) how learned aversions varied between the 2 consumer species we investigated.

\section{MATERIALS AND METHODS}

The lemon drop sea slug Doriopsilla pharpa is bright orange, reaches a length of $2.5 \mathrm{~cm}$, and occurs on oyster shell communities along the east coast of the USA. Eggs, juveniles, and adults inhabit loose shells colonized by their reported prey, the yellow boring sponge Cliona celata (Guida 1976, Eyster \& Stancyk 1981). D. pharpa is usually found on subtidal shell rubble in tidal rivers and creeks with high flow and steep banks (J. Long pers. obs.). All D. pharpa used in these experiments were collected from shallow subtidal areas of

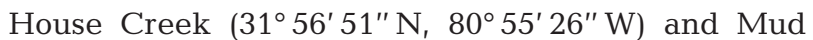

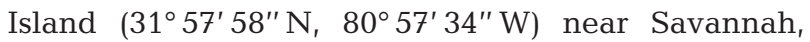
Georgia.

Palatability of nudibranch. Nudibranch susceptibility to the natural suite of consumers occurring in the field was assessed by tethering nudibranchs and similar-sized portions of squid mantle in the field. Similar procedures have been used to assess field predation on benthic invertebrates (Rogers et al. 2002), and may be particularly useful in turbid habitats where direct observations of predation are difficult. Tethers consisted of fishing hooks taped every $10 \mathrm{~cm}$ along weighted $220 \mathrm{~cm}$ long PVC pipes. Weights kept tethered prey close to their benthic habitats. On 12 and 13 September 2002, 10 nudibranchs and 10 squid pieces were randomly interspersed at $10 \mathrm{~cm}$ intervals along each of 4 weighted PVC pipes. On both days, 2 PVC pipes were placed $5 \mathrm{~m}$ apart in known nudibranch habitats at Mud Island. The presence or absence of food was recorded after 2 to $3 \mathrm{~h}$, and squid pieces and nudibranchs were examined for evidence of partial predation. Because many pieces of squid were removed from the tethers in the field, we tested if loss of squid pieces would have occurred due to flow alone. We tethered 20 squid pieces on each of 2 PVC pipes and placed these in a racetrack flume at flow rates typical of tidal creeks like our field test-site (M. Ferner pers. comm.). Flow durations and rates were $1 \mathrm{~h}$ at a flow rate of $5 \mathrm{~cm} \mathrm{~s}^{-1}$, then $1 \mathrm{~h}$ at $30 \mathrm{~cm} \mathrm{~s}^{-1}$, and then $24 \mathrm{~h}$ at $0 \mathrm{~cm} \mathrm{~s}^{-1}$.

To determine the palatability of nudibranchs to different co-occurring consumers, we collected lesser blue crabs Callinectes similus $(\mathrm{N}=7)$, Atlantic mud crabs Panopeus herbstii $(\mathrm{N}=31)$, mummichogs Fundulus heteroclitus ( $\mathrm{N}=14 ; 6$ to $8 \mathrm{~cm}$ long) and striped blennies Chasmodes bosquianus $(\mathrm{N}=29 ; 6$ to $8 \mathrm{~cm}$ long) from oyster reefs and used these consumers in laboratory feeding-assays. Consumers were maintained individually in 0.5 or 2.41 plastic containers in a flow-through seawater system, except $P$. herbstii, which were maintained in closed containers because of space limitation. During laboratory acclimation, most consumer species could be trained to feed on palatable food offered via a pipet or forceps. Consumers not previously fed Doriopsilla pharpa tissue or extracts were considered 'naïve', although they may have fed on the nudibranch in the field before collection. If we previously fed $D$. pharpa tissue or extracts to consumers, these consumers were considered 'experienced'. Three $\mathrm{h}$ before feeding assays, naïve crabs and fishes were fed to satiation on commercial crayfish food or frozen brine shrimp, respectively, thus ensuring that consumers did not consume defended food due to unnatural levels of hunger (Cronin \& Hay 1996, Thacker et al. 1997). 
Except for Panopeus herbstii, during feeding assays, individual consumers were first offered a palatable control food; 1 min later, they were offered a nudibranch. Finally, a second control was offered to confirm that avoidance of nudibranchs was not due to satiation. A different procedure was adopted for $P$. herbstii because they could not be trained to accept food from forceps and because they took longer to feed. Each $P$. herbstii was simultaneously offered a control food and a small nudibranch; $13 \mathrm{~h}$ later, these foods were assessed as missing (=eaten) or still remaining. For all assays, control food was created by incorporating freeze-dried squid ( $5 \%$ total wet mass) into a sodium alginate solution $(2 \%$ total wet mass; see Hay et al. 1998 for procedures), and dyeing this with food coloring to increase visibility. This mixture was injected through a syringe into a $0.25 \mathrm{M} \mathrm{CaCl}_{2}$ solution, creating a 'noodle' with the consistency of cooked pasta which was cut into similar-sized pellets. Consumer behaviors were scored as accepted (consumer ingested food), rejected (consumer took food into its mouth, forcefully expelled the food, and failed to reingest it after $1 \mathrm{~min}$ ), or ignored (consumer never tasted the food). After assays, containers were checked periodically for regurgitation of accepted food.

To confirm that our artificial food was nutritionally similar to nudibranchs, we measured the caloric content of squid-based pellets, tuna-based pellets, and Doriopsilla pharpa ( $\mathrm{N}=5$ for each). We combined 4 individual $D$. pharpa per replicate to ensure sufficient material for calorimetric analysis.

Tests of chemical defenses. We assessed potential chemical defenses of the nudibranch by evaluating the palatability of nudibranch extracts. The same procedures used to assess palatability of whole nudibranchs in the laboratory were used to assess palatability of chemical extracts, with 2 exceptions: (1) treatment food consisted of control food with nudibranch extracts added and (2) because extracts were dissolved in ether when added to food, an equivalent volume of extractfree ether was added to control food. Extracts were prepared by homogenizing and soaking 1 to $2 \mathrm{ml}$ (wet volume) of nudibranchs in acetone for several hours. Removal of acetone via rotary evaporation was followed by partition between dichloromethane (DCM) and water. After removing solvents via rotary evaporation (for DCM removal) and freeze-drying (for water removal), the lipid-soluble (DCM) extract was re-dissolved in a known amount of ether and the water-soluble extract was re-dissolved in a known amount of water so that appropriate amounts of each extract could be added to experimental food.

When preparing food, the ether-soluble extract was placed in a small vial, the ether was removed by gentle aeration with nitrogen gas, and the remaining extract was mixed with squid paste. For water-soluble extracts, the water with the extract replaced part of the water normally used in the recipe for the food. For this experiment, extracts were added to squid pellets at $2 \times$ natural volumetric concentrations in order to counteract possible losses of compound in the initial extraction and separation procedures. After finding initial deterrence in this test, all subsequent tests were conducted at natural (not $2 \times$ natural) volumetric concentrations. To test extracts at natural volumetric concentrations, extracts from a given volume of nudibranchs were added to an equivalent volume of treatment food and offered to consumers as described above. Naïve Chasmodes bosquianus ( $\mathrm{N}=16$ ) were first offered lipid-soluble extracts and controls on Day 1. Water-soluble extracts and controls were offered the next day. Fish were watched for regurgitation or other unusual behavior for several minutes after accepting pellets. They were checked again after several hours and on the following day.

When Chasmodes bosquianus were offered food treated with lipid-soluble extracts, we observed regurgitation, suggesting the potential for the development of learned aversions. To test whether fish would learn to avoid this food, we conducted short-term learning assays with Fundulus heteroclitus and C. bosquianus. Lipid-soluble extracts were incorporated into squidbased pellets at natural volumetric concentrations. Palatability of these pellets versus control pellets without extracts (solvent only) was measured daily for naïve F. heteroclitus $(\mathrm{N}=20)$ and $C$. bosquianus $(\mathrm{N}=$ 10) for 3 consecutive days. All fishes were fed brine shrimp until satiation $3 \mathrm{~h}$ before experimental feeding. Control pellets were offered first and a treatment pellet was offered $90 \mathrm{~s}$ later. After both pellets had been offered, each fish was watched for 5 min before we proceeded to the next fish. Regurgitation was monitored for an additional $45 \mathrm{~min}$, and rejected and regurgitated pellets were removed.

To purify the compound responsible for defending nudibranchs from consumers, we used bioassayguided fractionation. Lipid-soluble extracts from the nudibranch's mantle margin, prepared as described above, were separated using preparative, normalphase, thin-layer chromatography (TLC). These fractions were added to squid-based pellets and fed to experienced Fundulus heteroclitus ( $\mathrm{N}=11$ to 13), because this species learned to avoid the nudibranch extract itself rather than the taste of the food with which the extract was associated. Unpalatable fractions were further purified by preparative TLC until 1 deterrent compound was apparent using TLC. ${ }^{1} \mathrm{H}$-nuclear magnetic resonance (NMR) and mass spectroscopy were used to identify the structure of this deterrent compound. 
The deterrent compound purified from the nudibranchs $\left({ }^{1} \mathrm{H}\right.$-NMR estimate of purity = 99\%) was offered to naïve Chasmodes bosquianus to determine whether they would develop aversion to food treated only with this compound. Fish were collected late in the season when they were rare, so only 11 fish could be collected. To increase the power of our analyses, each fish was tested both as a control and treatment fish at different times. In the first run of this experiment, fish were fed tuna-based food, and 6 fish were assigned to the treatment group (receiving 1 pellet with compound and 1 pellet without) and 5 to the control group (receiving 2 pellets without compound). In the second run of the experiment, which immediately followed the first, the assigned groups were switched, the base food was switched to squid instead of tuna, and the procedure was repeated. Previous experiments had demonstrated that switching from tunabased to squid-based food 'deleted' the previously learned avoidance of food by this species because it avoided treated food based on the taste of the base food rather than on the taste of the specific metabolite added (Long 2004). For the first 3 d of both experiments, all individuals were trained to feed on pellets without nudibranch extracts. For $5 \mathrm{~d}$ after this preconditioning period, red pellets (in order that we could see if these were regurgitated) fed to treatment fish contained the purified compound at natural volumetric concentrations, and all other pellets had solvent added as a control. (To simplify data presentation, these data are combined in Fig. 5.)

Data analyses. Tethering data were pooled and analyzed using a $G$-test with a Yates correction for continuity (Zar 1999). Acceptance frequencies of consumers feeding on Doriopsilla pharpa, extracts, and purified compound compared to feeding on controls were analyzed by Fisher's exact test. Caloric content of nudibranchs and control food were compared using ANOVA. For learning assays, a changing proportion over time was tested for a linear trend using chisquare, as recommended by Zar (1999).

\section{RESULTS}

\section{Nudibranch palatability}

The nudibranch Doriopsilla pharpa was unpalatable to mixed species of consumers in the field and to 2 species of crabs and 2 species of fishes in laboratory assays (Fig. 1). When tethered in the field, $78 \%$ of squid pieces, but only $10 \%$ of the D. pharpa individuals, were removed $(\mathrm{p}<0.001)$. Neither remaining squid pieces nor remaining $D$. pharpa showed signs of partial predation. Because all squid pieces remained tethered under realistic flow speeds in flume trials, it is unlikely that field losses were due to physical processes alone. Laboratory assays corroborated field patterns. Living D. pharpa were rejected by all naïve Callinectes similus ( $\mathrm{p}=0.001)$, Fundulus heteroclitus $(\mathrm{p}<0.001)$, and Chasmodes bosquianus ( $\mathrm{p}<0.001)$. These consumers accepted all control food. No Panopeus herbstii consumed nudibranchs, but $48 \%$ of these crabs consumed control food ( $\mathrm{p}<0.001)$.

The control food used in our assays were similar to Doriopsilla pharpa in caloric value. The caloric content per volume of $D$. pharpa $\left(346 \pm 11 \mathrm{cal} \mathrm{ml}^{-1}\right.$; mean \pm $1 \mathrm{SE}$ ) and both artificial diets (tuna-based pellets = $329 \pm 3 \mathrm{cal} \mathrm{ml}^{-1}$; squid-based pellets $=326 \pm 2 \mathrm{cal} \mathrm{ml}^{-1}$ ) was not significantly different $(p=0.127)$.

\section{Nudibranch chemical defense and learned aversions}

Neither lipid-soluble nor water-soluble fractions of nudibranch extracts initially deterred feeding by striped blennies (Fig. 2, p > 0.999). However, 67\% of the blennies accepting food containing lipid-soluble extracts regurgitated; no control pellets were regurgitated (Fig. 2, p < 0.001). Water-soluble, nudibranch extracts were palatable to striped blennies experienced with lipid-soluble extracts (Fig. 2, p > 0.999), and none of these pellets were regurgitated. All fish accepted control food, with the exception of the

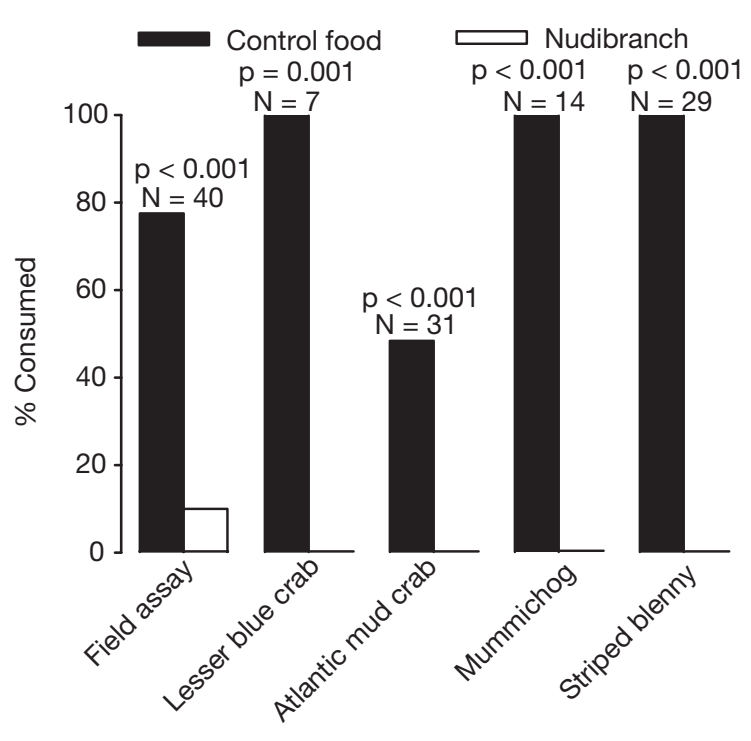

Fig. 1. Callinectes similus, Panopeus herbstii, Fundulus heteroclitus and Chasmodes bosquianus. Percentage of nudibranch Doriopsilla pharpa consumed relative to similar-sized portions of squid mantle by $2 \mathrm{crab}$ and fish species. Analyses were by $G$-test for field assay and 2-tailed Fisher's exact test for individual consumers 


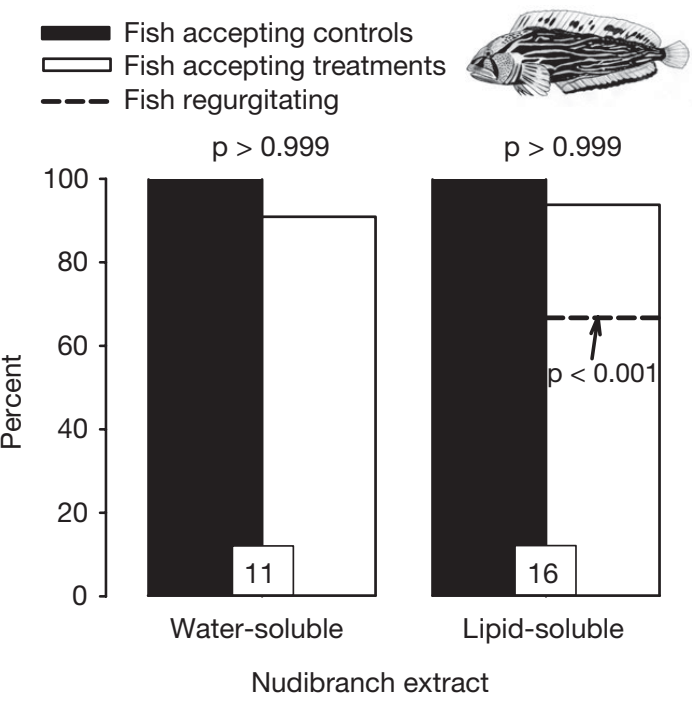

Fig. 2. Chasmodes bosquianus. Palatability of water-soluble and lipid-soluble nudibranch (Doriopsilla pharpa) extracts fed to striped blennies at $2 \times$ natural concentration relative to palatable control food. Dashed line indicates percentage of treatment fish regurgitating accepted food (no control fish regurgitated). Sample sizes given inside bars. Analyses were by 2-tailed Fisher's exact test

experiment with water-soluble extracts where 5 individuals avoided control food. These 5 fish may have avoided control food due to satiation or learned aversion associated with regurgitation of lipid-soluble food on the previous day. They were therefore excluded from analyses, reducing the sample size from 16 to 11 .

When control food and food treated with lipid-soluble extract were fed to Fundulus heteroclitus and Chasmodes bosquianus for 3 consecutive days, C. bosquianus consumed both foods on Day 1 (Fig. 3A, p = 0.21 ). However, $71 \%$ of $C$. bosquianus accepting treatment pellets regurgitated these after an average of $12.7 \pm 5.8$ min (mean $\pm 1 \mathrm{SE}$ ), with a range of 2.5 to $39.3 \mathrm{~min}$. The willingness of $C$. bosquianus to accept either treatment or control food declined dramatically after 1 to $2 \mathrm{~d}$ exposure to this food $(\mathrm{p}<0.005$ and $\mathrm{p}<$ 0.05 for the treatment and control food, respectively; chi-square). After Day 1, 3 C. bosquianus died, reducing $\mathrm{N}$ from 10 to 7 . Feeding patterns for $F$. heteroclitus differed from those for $C$. bosquianus. On Day 1 , significantly more $F$. heteroclitus accepted control than treatment pellets (Fig. $3 \mathrm{~B}, \mathrm{p}=0.02$ ), and $F$. heteroclitus never regurgitated any pellets. The willingness of $F$. heteroclitus to accept food containing lipid-soluble extracts declined after the first feed $(p<$ 0.005 ; chi-square). The willingness of $F$. heteroclitus to accept control pellets did not change with time $(0.10<$ $\mathrm{p}<0.26$; chi-square).

\section{Chemistry of deterrence}

When the organic extract of the nudibranch was fractionated and tested for effects on feeding by Fundulus heteroclitus, 2 adjacent fractions showed deterrence, with most of the activity associated with Fraction B (Fig. $4, \mathrm{p}<0.001)$. Some deterrence was associated with Fraction C, possibly because of incomplete separation of compounds in B and C. Fraction B was further separated into 2 fractions, with Fraction $B_{1}$ being palatable $(p=0.500)$ and Fraction $B_{2}$ being unpalatable $(p<$ $0.001)$. TLC analysis suggested that $B_{2}$ could be a pure compound. Mass spectral analysis (using electron impact ionization) suggested a molecule with a molecular weight of 234.16287, corresponding to a molecular formula of $\mathrm{C}_{15} \mathrm{H}_{22} \mathrm{O}_{2}$ (expected mass 234.1619). The ${ }^{1} \mathrm{H}-\mathrm{NMR}$ spectrum, recorded in deuterated chloroform at $300 \mathrm{MHz}$, indicated chemical shifts at 9.52 (doublet), 9.44 (singlet), 7.15 (multiplet), 2.81 (multiplet), 2.56-2.22 (multiplet), 1.90-1.10 (multiplet), 0.94 (singlet), 0.92 (singlet), and 0.90 (singlet). These data were consistent with identifying this compound as the known sesquiterpene, polygodial (Barnes \& Loder 1962; struc-

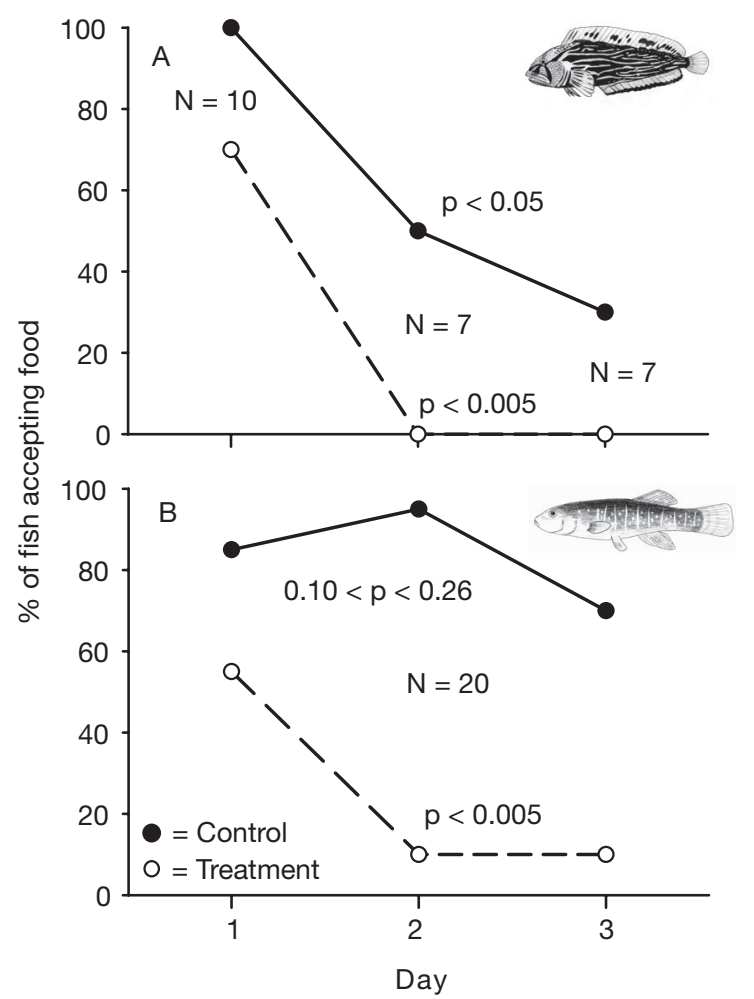

Fig. 3. (A) Chasmodes bosquianus and (B) Fundulus heteroclitus. Short-term learning. Palatability of treated food (palatable food containing lipid-soluble, nudibranch Doriopsilla pharpa extracts at natural concentrations) and untreated control food over 3 consecutive days. Changing response over time was evaluated using chi-square test for linear trend and significant changes are indicated by $p$-values $<0.05$ 


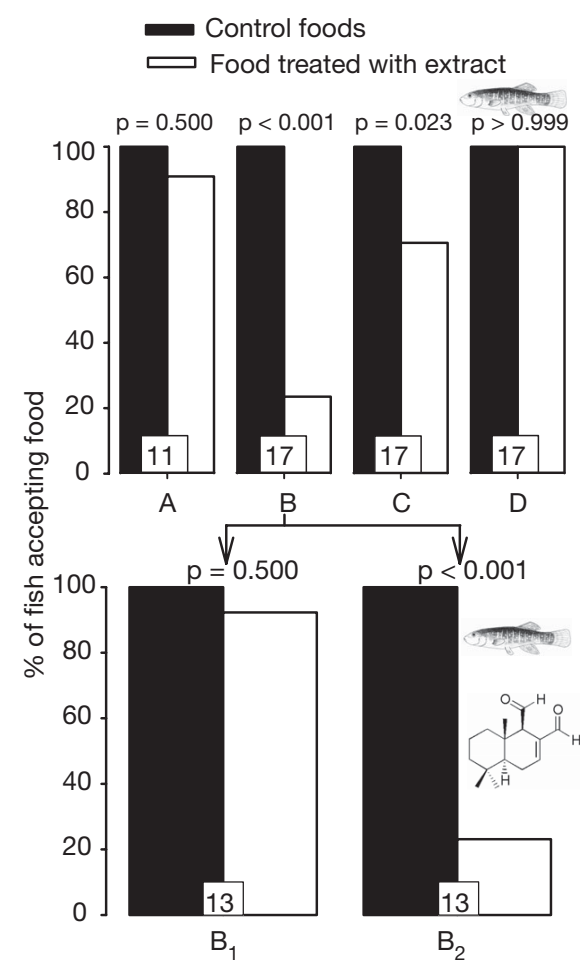

Fig. 4. Fundulus heteroclitus. Palatability of fractions from lipid-soluble extract of Doriopsilla pharpa fed to mummichogs at natural concentrations. Sample sizes given inside bars. Analyses were by 1-tailed Fisher's exact test

ture shown in Figs. 4 \& 5). The yield of polygodial from the extraction of whole nudibranchs was $0.39 \mathrm{mg} \mathrm{ml}^{-1}$ of wet nudibranch tissue.

We then tested this compound (acquired via isolation from the nudibranch) at natural concentrations to see if it alone could account for the effects of the lipidsoluble extract on Chasmodes bosquianus feeding; we detected patterns similar to those seen in tests of the lipid-soluble extract. On the first day that food with polygodial was offered, fish ate all treatment and control food with equal frequency (Fig. 5). However, on the following days, treatment fish decreased their feeding on both treatment and control foods $(p<0.001$ and $p<0.005$, respectively), while feeding by control fish did not change over time $(0.10<\mathrm{p}<0.25$, both foods). C. bosquianus appeared to avoid the general taste of food containing polygodial, not just food treated with this compound. Unlike assays with the crude extract, C. bosquianus never regurgitated food treated with polygodial alone.

\section{DISCUSSION}

How consumers learn to accept or avoid new food is better understood for terrestrial (e.g. Provenza et al.
2003, Villalba et al. 2004) than for marine consumers, for which studies of diet-learning have been infrequent. Understanding how marine consumers respond to new food is important for predicting changes in food-web dynamics because of the large numbers of introduced species (Ruiz et al. 2000), the frequent range expansions (Barry et al. 1995, Parker \& Dixon 1998), and the large-scale declines in some common prey species (Lessios 1988, Miller et al. 2002) that are occurring in marine systems. These changes in the identity and abundance of potential prey will allow, or sometimes force, shifts in consumer food-use. The behavior underlying such shifts is poorly understood, despite some studies addressing aspects of consumerlearning in marine systems (e.g. Gerhart 1991, Lindquist \& Hay 1995, Thacker et al. 1997). However, it is clear that behavior-based shifts in prey selection can sometimes have profound effects on the structure and function of marine communities over large spatial scales (Estes et al. 1998).

Although the nudibranch Doriopsilla pharpa was unpalatable to all co-occurring consumers tested in the

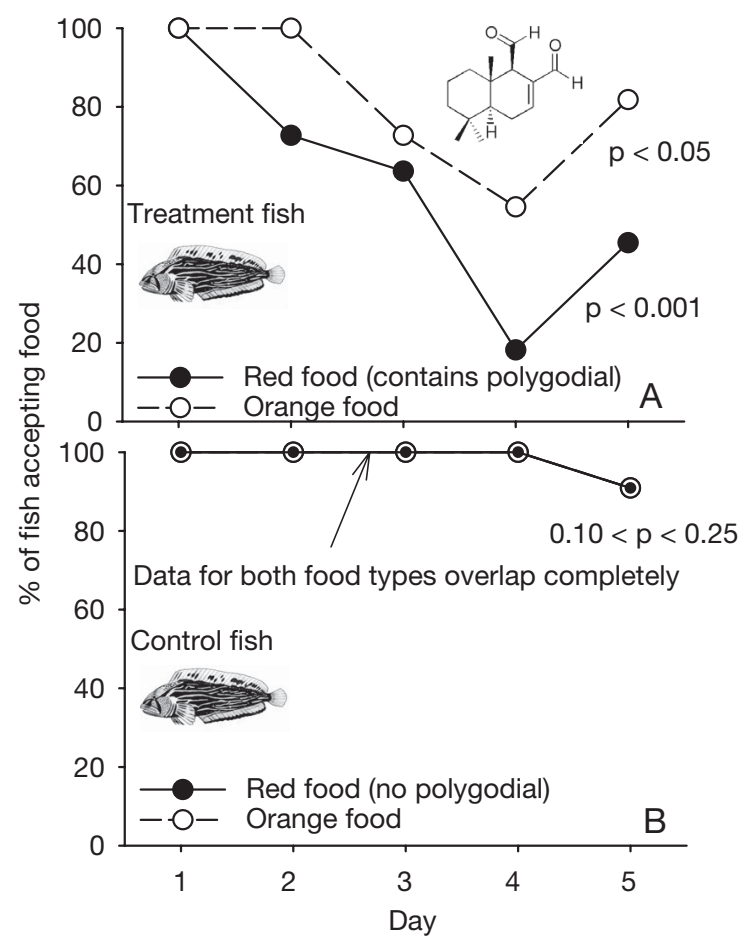

Fig. 5. Chasmodes bosquianus. Aversive learning caused by polygodial, showing palatability of red and orange pellets to (A) treatment and (B) control fish for each day. Red pellets fed to treatment fish contained polygodial at natural concentrations, while those fed to control fish did not. Orange pellets never contained polygodial for either fish group. Changing response over time was evaluated using chi-square test for linear trend; significant changes indicated by p-values $<0.05$ 
laboratory and to a natural suite of consumers in the field (Fig. 1), 2 generalist fishes did not immediately avoid extracts of the nudibranch when it was incorporated into otherwise palatable food. However, both species rapidly developed aversions to food containing (Fundulus heteroclitus), or associated with (Chasmodes bosquianus), lipid-soluble extracts from the nudibranch; they also learned to avoid the specific compound polygodial (Figs. 4 \& 5). Although both consumers quickly learned to avoid defended food, the extracts affected the fishes differently, inducing regurgitation in $C$. bosquianus but not in $F$. heteroclitus, and the fishes seemed differentially able to detect the active metabolite using taste. F. heteroclitus could detect the active compound and avoid only food containing the actual deterrent chemical, while $C$. bosquianus learned to avoid the general taste of aversive food (e.g. food tasting like squid), even when half of these foods lacked aversive compounds and would have been useful as food (Figs. 3 \& 5). Similar patterns of avoidance of specific food (as opposed to specific compounds within this food) when physiological distress occurs after consumption have been documented in consumers as diverse as birds, snakes, rats, sheep and humans (Wilcoxon et al. 1971, Burghardt et al. 1973, Nicolaus et al. 1983, Provenza et al. 2003, Villalba et al. 2004).

Polygodial protects Doriopsilla pharpa from fish predation. This is the first study to isolate polygodial from D. pharpa and to report polygodial's role in learned aversions. Polygodial may serve a similar role in several unrelated organisms, as it occurs in (1) terrestrial plants such as Polygonum hydropiper, in which this compound was first discovered (Barnes \& Loder 1962), and in trees within the Canallaceae (Kubo \& Ganjian 1981); (2) freshwater macrophytes (J. Kubanek pers. comm.); (3) several species of dendrodorid nudibranchs, including several members of the Doriopsilla genus (Cimino et al. 1983, Okuda et al. 1983); and (4) the sponge genus Dysidea (Paul et al. 1997). This broad distribution of polygodial across many unrelated prey suggests that it has evolved independently on numerous occasions or that it might be produced by microbial symbionts associated with numerous different prey (e.g. Miyazawa \& Noguchi 2001, Piel et al. 2004). The hypothesis of production via microbial symbionts seems less likely than convergent evolution, given precursor labeling experiments suggesting de novo biosynthesis in nudibranchs (Cimino et al. 1983); however, such experiments do not unambiguously rule out the possibility of microbial involvement.

While a previous study with fishes suggested possible ecological functions of polygodial (Cimino et al. 1982), that study used consumers that would never encounter these prey in nature, so ecological roles for the compounds were uncertain. Ecological functions are best demonstrated when natural compounds are presented in realistic ways to co-occurring consumers (Pawlik et al. 1995, Hay 1996, Bernays \& Chapman 2000). In our study, co-occurring consumer species in the laboratory and mixed species of consumers in the field all avoided consuming Doriopsilla pharpa, clearly demonstrating that it was unpalatable. Laboratory tests confirmed that this was due to chemical traits, and both fishes were deterred by polygodial alone, clearly demonstrating that this compound serves as a defense against ecologically realistic consumers. The effects of this compound against other fishes (Cimino et al. 1982) and its occurrence in a diverse group of sedentary prey (trees, aquatic macrophytes, sponges) both suggest that it may serve as an effective defense against numerous generalist consumers. However, polygodial may not be the complete chemical arsenal of these prey species. It is interesting that polygodial alone did not induce regurgitation in striped blennies, but lipidsoluble extracts did; this suggests that other chemicals may play additional, or synergistic, roles in defense and in causing regurgitation.

The short-term physiological effects of consuming aversive food differed between the 2 fish species we assayed. Fundulus heteroclitus never regurgitated food treated with nudibranch extracts, while most Chasmodes bosquianus regurgitated treated food after an average of $\sim 13 \mathrm{~min}$, a period similar to previous reports for other marine fishes consuming chemically defended food: within 1 to $2 \mathrm{~h}$ (Lindquist \& Hay 1995), 1.52 min (Gerhart 1984), and 7.25 min (Gerhart 1984). Short delays between ingestion and illness create strong learned aversions (Gelperin 1975). Our results disagree with the hypothesis that materials that induce regurgitation in a given fish species tend also to induce emetic responses in other fish species (Gerhart \& Coll 1993).

Our test fishes used different chemical cues when developing learned aversions, possibly as a function of how the compounds affected the different fishes. Although both fishes learned to avoid food with nudibranch extracts, Chasmodes bosquianus learned to avoid food tasting or smelling like aversive food, but Fundulus heteroclitus learned to avoid the taste of the aversive extract or compound alone. C. bosquianus may be unable to detect these compounds, forcing this species to exploit other cues, such as the general taste of the food (i.e. squid). Alternatively, the use of different cues may be related to how the compounds affected the consumers (Nicolaus et al. 1983). C. bosquianus took a conservative strategy by associating the taste of food with physiological distress and then avoiding all food tasting or smelling like defended food, even when the food lacked aversive compounds. F. heteroclitus, how- 
ever, learned to detect and respond to the specific taste of the extract, or of polygodial, alone. This interspecific difference was not a simple issue of dosage (because both fishes were of similar size and received equal concentrations of extracts or compound in the test food), and was not due to an inability of $F$. heteroclitus to regurgitate food $; F$. heteroclitus regurgitated food treated with defensive extracts from marine worms (C. Kicklighter pers. comm.).

Although both fishes learned to avoid food types that contained, or sometimes contained, bioactive compounds, the difference in the cues used to achieve this could result in the fishes differentially affecting prey populations and being differentially affected by abundance of their potential prey. If the ability of Fundulus heteroclitus to taste and avoid specific metabolites and the reliance of Chasmodes bosquianus on more general taste cues instead of the specific active compound are general traits of these 2 fishes, then (1) under conditions of food limitation, F. heteroclitus would be advantaged over C. bosquianus due to its greater ability to discriminate between defended and undefended individuals, and (2) prey attacked by $C$. bosquianus would have the option of escaping predation via 'taste mimicry' (e.g. in our experiments, tasting like squid even if not chemically defended) while prey attacked by $F$. heteroclitus would not be selected to use this option. As our understanding of chemical defenses of marine prey increases, it is becoming increasingly common to find that there are sometimes great intraspecific differences in chemical defenses among populations, or even among individuals within a population (e.g. Kubanek et al. 2003, Taylor et al. 2003). Such variance could allow taste mimicry to protect undefended individuals if they were attacked by $C$. bosquianus, but would not be an effective strategy against $F$. heteroclitus.

Learned food aversions should be common in marine habitats given the relative prevalence of generalist consumers in marine versus terrestrial systems (Hay 1992) and the predominance of learned food aversions in generalist consumers. In terrestrial systems, generalist feeders such as polyphagous insects (Lee \& Bernays 1988) and frugivorous bats (Ratcliffe et al. 2003) learn to avoid food after a negative experience, while more specialist feeders such as oligophagous insects (Dethier \& Yost 1979) and vampire bats do not (Ratcliffe et al. 2003). By conducting comparative studies of learning among consumers, we can improve our understanding of how prey may exploit the learning behavior of their consumers, and we can better understand how interspecific variance in learned aversions of marine consumers may affect their impact on prey populations and marine community organization.
Acknowledgements. Support was provided by EPA STAR fellowship U-91599501-0 (J.D.L.) and the Teasley Endowment to Georgia Institute of Technology. J. Kubanek assisted with compound identification; C. Kicklighter and C. Robertson helped with laboratory experiments; M. Ferner provided time in the flume at Skidaway Institution of Oceanography; A. Hollebone, E. Kinard, T. Recicar, and S. Savage helped with collections. Comments by 3 reviewers improved the manuscript.

\section{LITERATURE CITED}

Avila C (1995) Natural products of opisthobranch mollusks: a biological review. Oceanogr Mar Biol Annu Rev 33: 487-559

Avila C, Paul VJ (1997) Chemical ecology of the nudibranch Glossodoris pallida: is the location of diet-derived metabolites important for defense? Mar Ecol Prog Ser 150: 171-180

Barnes CS, Loder JW (1962) Structure of polygodial: a new sesquiterpene dialdehyde from Polygonum hydropiper. Aust J Chem 15:322-327

Barry JP, Baxter CH, Sagarin RD, Gilman SE (1995) Climaterelated, long-term faunal changes in a California rocky intertidal community. Science 267:672-675

Berenbaum MR, Miliczky E (1984) Mantids and milkweed bugs - efficacy of aposematic coloration against invertebrate predators. Am Midl Nat 111:64-68

Bernays EA, Chapman RF (2000) Plant secondary compounds and grasshoppers: beyond plant defenses. J Chem Ecol 26: 1773-1794

Bernstein IL (1978) Learned taste aversions in children receiving chemotherapy. Science 200:1302-1303

Burghardt GM, Wilcoxon HC, Czaplick JA (1973) Conditioning in garter snakes - aversion to palatable prey induced by delayed illness. Anim Learn Behav 1:317-320

Cauley MJ, Schluter D (2003) Predators favor mimicry in a tropical reef fish. Proc R Soc Ser B 270:667-672

Cimino G, Ghiselin M (1999) Chemical defense and evolutionary trends in biosynthetic capacity among dorid nudibranchs (Mollusca: Gastropods: Opisthobranchia). Chemoecology 9:187-207

Cimino G, Derosa S, Destefano S, Sodano G (1982) The chemical defense of four Mediterranean nudibranchs. Comp Biochem Physiol B 73:471-474

Cimino G, Derosa S, Destefano S, Sodano G, Villani G (1983) Dorid nudibranch elaborates its own chemical defense. Science 219:1237-1238

Cronin G, Hay ME (1996) Susceptibility to herbivores depends on recent history of both the plant and animal. Ecology 77:1531-1543

Cronin G, Hay ME, Fenical W, Lindquist N (1995) Distribution, density, and sequestration of host chemical defenses by the specialist nudibranch Tritonia hamnerorum found at high densities on the sea fan Gorgonia ventalina. Mar Ecol Prog Ser 119:177-189

Crossland MR (2001) Ability of predatory native Australian fishes to learn to avoid toxic larvae of the introduced toad Bufo marinus. J Fish Biol 59:319-329

Dethier VG, Yost MT (1979) Oligophagy and absence of food aversion learning in tobacco hornworms, Manduca sexta. Physiol Entomol 4:125-130

Estes JA, Tinker MT, Williams TM, Doak DF (1998) Killer whale predation on sea otters linking oceanic and nearshore ecosystems. Science 282:473-476

Eyster LS, Stancyk SE (1981) Reproduction, growth and 
trophic interactions of Doriopsilla pharpa Marcus in South Carolina. Bull Mar Sci 31:72-82

Faulkner DJ, Ghiselin MT (1983) Chemical defense and evolutionary ecology of dorid nudibranchs and some other opisthobranch gastropods. Mar Ecol Prog Ser 13:295-301

Garcia J, Hankins WG, Rusiniak KW (1974) Behavioral regulation of milieu interne in man and rat. Science 185: 824-831

Gelperin A (1975) Rapid food aversion learning by a terrestrial mollusk. Science 189:567-570

Gerhart DJ (1984) Prostaglandin A2 - an agent of chemical defense in the Caribbean gorgonian Plexaura homomalla. Mar Ecol Prog Ser 19:181-187

Gerhart DJ (1991) Emesis, learned aversion, and chemical defense in octocorals - a central role for prostaglandins. Am J Physiol 260:R839-R843

Gerhart DJ, Coll JC (1993) Pukalide, a widely distributed octocoral diterpenoid, induces vomiting in fish. J Chem Ecol 19:2697-2704

Guida VG (1976) Sponge predation in oyster reef community as demonstrated with Cliona celata Grant. J Exp Mar Biol Ecol 25:109-122

Hay ME (1992) The role of seaweed chemical defenses in the evolution of feeding specialization and in the mediation of complex interactions. In: Paul VJ (ed) Ecological roles for marine natural products. Comstock Publishing Associates, Ithaca, NY, p 93-118

Hay ME (1996) Marine chemical ecology: what's known and what's next? J Exp Mar Biol Ecol 200:103-134

Hay ME, Stachowicz JJ, Cruz-Rivera E, Bullard S, Deal MS, Lindquist N (1998) Bioassays with marine and freshwater macroorganisms. In: Haynes KF, Millar JG (eds) Methods in chemical ecology, Vol 2. Chapman \& Hall, New York, p 39-141

Howard RW, Blomquist GJ (2005) Ecological, behavioral, and biochemical aspects of insect hydrocarbons. Annu Rev Entomol 50:371-393

Kubanek J, Graziani EI, Andersen RJ (1997) Investigations of terpenoid biosynthesis by the dorid nudibranch Cadlina luteomarginata. J Org Chem 62:7239-7246

Kubanek J, Jensen PR, Keifer PA, Sullards C, Collins DO, Fenical W (2003) Seaweed resistance to microbial attack: a targeted chemical defense against marine fungi. Proc Natl Acad Sci USA 100:6916-6921

Kubo I, Ganjian I (1981) Insect antifeedant terpenes, hot-tasting to humans. Experientia 37:1063-1064

Laska M, Metzker K (1998) Food avoidance learning in squirrel monkeys and common marmosets. Learn Mem 5: 193-203

Launchbaugh KL, Provenza FD (1993) Can plants practice mimicry to avoid grazing by mammalian herbivores? Oikos 66:501-506

Lee JC, Bernays EA (1988) Declining acceptability of a food plant for the polyphagous grasshopper Schistocerca americana: the role of food aversion learning. Physiol Entomol 13:291-301

Lessios HA (1988) Mass mortality of Diadema antillarum in the Caribbean - what have we learned? Annu Rev Ecol Syst 19:371-393

Lindquist N, Hay ME (1995) Can small rare prey be chemically defended - the case for marine larvae. Ecology 76 : $1347-1358$

Long JD (2004) Plasticity of consumer-prey interactions in the sea. PhD dissertation, Georgia Institute of Technology, Atlanta, GA

Miller MW, Bourque AS, Bohnsack JA (2002) An analysis of the loss of acroporid corals at Looe Key, Florida, USA:
1983-2000. Coral Reefs 21:179-182

Miyazawa K, Noguchi T (2001) Distribution and origin of tetrodotoxin. J Toxicol Toxin Rev 20:11-33

Nicolaus LK, Cassel JF, Carlson RB, Gustavson CR (1983) Taste-aversion conditioning of crows to control predation on eggs. Science 220:212-214

Okuda RK, Scheuer PJ, Hochlowski JE, Walker RP, Faulkner DJ (1983) Sesquiterpenoid constituents of eight porostome nudibranchs. J Org Chem 48:1866-1869

Parker RO Jr, Dixon RL (1998) Changes in a North Carolina reef fish community after 15 years of intense fishing global warming implications. Trans Am Fish Soc 127: 909-920

Paul VJ, Seo Y, Cho KW, Rho JR, Shin J, Bergquist PR (1997) Sesquiterpenoids of the drimane class from a sponge of the genus Dysidea. J Nat Prod (Lloydia) 60:1115-1120

Pawlik JR, Kernan MR, Molinski TF, Harper MK, Faulkner DJ (1988) Defensive chemicals of the Spanish dancer nudibranch Hexabranchus sanguineus and its egg ribbons: macrolides derived from a sponge diet. J Exp Mar Biol Ecol 119:99-109

Pawlik JR, Chanas B, Toonen RJ, Fenical W (1995) Defenses of Caribbean sponges against predatory reef fish. 1. Chemical deterrency. Mar Ecol Prog Ser 127:183-194

Penney BK (2002) Lowered nutritional quality supplements nudibranch chemical defense. Oecologia 132:411-418

Piel J, Hui DQ, Wen GP, Butzke D, Platzer M, Fusetani N, Matsunaga S (2004) Antitumor polyketide biosynthesis by an uncultivated bacterial symbiont of the marine sponge Theonella swinhoei. Proc Natl Acad Sci USA 101: 16222-16227

Provenza FD (1995) Tracking variable environments - there is more than one kind of memory. J Chem Ecol 21:911-923

Provenza FD, Villalba JJ, Dziba LE, Atwood SB, Banner RE (2003) Linking herbivore experience, varied diets, and plant biochemical diversity. Small Ruminant Res 49: 257-274

Ratcliffe JM, Fenton MB, Galef BG (2003) An exception to the rule: common vampire bats do not learn taste aversions. Anim Behav 65:385-389

Rogers CN, de Nys R, Steinberg PD (2002) Effects of algal diet on the performance and susceptibility to predation of the sea hare Aplysia parvula. Mar Ecol Prog Ser 236:241-254

Ruiz GM, Fofonoff PW, Carlton JT, Wonham MJ, Hines AH (2000) Invasion of coastal marine communities in North America: apparent patterns, processes, and biases. Annu Rev Ecol Syst 31:481-531

Slattery MC, Avila C, Starmer J, Paul VJ (1998) A sequestered soft coral diterpene in the aeolid nudibranch Phyllodesmium guamensis. J Exp Mar Biol Ecol 226:33-49

Taylor RB, Lindquist N, Kubanek J, Hay ME (2003) Intraspecific variance in palatability and defensive chemistry of brown seaweeds: effects on herbivore fitness. Oecologia 136:412-423

Thacker RW, Nagle DG, Paul VJ (1997) Effects of repeated exposures to marine cyanobacterial secondary metabolites on feeding by juvenile rabbitfish and parrotfish. Mar Ecol Prog Ser 147:21-29

Thacker RW, Becerro MA, Lumbang WA, Paul VJ (1998) Allelopathic interactions between sponges on a tropical reef. Ecology 79:1740-1750

Villalba JJ, Provenza FD, Han GD (2004) Experience influences diet mixing by herbivores: implications for plant biochemical diversity. Oikos 107:100-109

Warburton K (2003) Learning of foraging skills by fish. Fish Fish 4:203-215

Wilcoxon HC, Dragoin WB, Kral PA (1971) Illness induced 
aversions in rat and quail: relative salience of visual and gustatory cues. Science 171:826-828

Yoerg SI (1991) Social feeding reverses learned flavor aversions in spotted hyenas (Crocuta crocuta). J Comp Psychol 105:185-189

Editorial responsibility: Joseph Pawlik (Contributing Editor), Wilmington, North Carolina, USA
Young CM, Bingham BL (1987) Chemical defense and aposomatic coloration in larvae of the ascidian Ecteinascidia turbinata. Mar Biol 96:539-544

Zar JH (1999) Biostatistical analysis. 4th edn. Prentice-Hall, Upper Saddle River, NJ

Submitted: December 6, 2004; Accepted: July 6, 2005

Proofs received from author(s): December 12, 2005 